\title{
ANALISA KEANDALAN SISTEM KELISTRIKAN 3 FASE PADA HOTEL BISANTA BIDAKARA SURABAYA
}

\author{
Disusun Oleh : \\ Rendi Nur Resmiawanto dan R. Ahmad Cholilurrahman \\ Laboratorium Teknik Tenaga Listrik, Jurusan Teknik Elektro, FTI, ITATS \\ Jalan Arief Rachman Hakim 100, Surabaya 60117 \\ Email: cholilurrahman_r@yahoo.com
}

\begin{abstract}
ABSTRAK
Permasalahannya ialah,bagaimana mengetahui pengaruh cadangan daya sistem terhadap tingkat gangguan selama sebulan di masing-masing lantai pada Hotel Bisanta Bidakara Surabaya.Hasil akhir menunjukkan indeks keandalaan berbasis sistem keandalaan pada Hotel Bisanta Bidakara, Surabaya maka besarnya untuk SAIDI (harga rata-rata) adalah 17,04 gangguan per lantai dalam 1 bulan.Dengan mengacu pada PT. PLN (Persero) Distribusi Jawa Timur, Cabang SurabayaTahun 2014, Area Surabaya selatan yang menetapkan Realisasi SAIDI 16,72 menit per pelanggan, maka besarnya SAIDI di Hotel Bisanta Bidakara, Surabaya masih jauh dari harapan yang diinginkan.Untuk SAIFI besarannya 2,1 jam per lantai, dengan mengacu pada PT. PLN (Persero) Distribusi Jawa Timur, Cabang Surabaya Tahun 2014, Area Surabaya Selatan yang menetapkan lama gangguan Realisasi SAIFI 0,018 menit per pelanggan, maka besarnya SAIFI di Hotel Bisanta Bidakara, Surabaya masih jauh dari harapan yang diinginkan.Dengan memperhatikan kedua hasil perhitungan di atas, maka di kategorikan sistem keandalaan di Hotel Bisanta Bidakara, Surabaya perlu di rehabilitasi keandalannya.
\end{abstract}

Kata kunci : Keandalan, sistem kelistrikan hotel.

\section{PENDAHULUAN}

Hotel merupakan sarana infrastruktur yang penting bagi sebagian masyarakat. Dalam hal ini Hotel Bisanta Bidakara termasuk kedalam hotel bintang 3 dengan gedung 7 lantai yang cukup diminati oleh sebagian masyarakat.Oleh sebab itu. untuk menunjang setiap kegiatan operasionalnya dibutuhkan suplai daya listrik yang tidak sedikit. Selain itu juga faktor keamanan dalam penyaluran dayanya sangatlah penting.

Untuk mengetahui distribusi tenaga listrik Hotel Bisanta Bidakara, Surabaya pada masing-masing lantai serta tingkat gangguan di masing-masing lantai, mulai dari Distribution Panel atau panel distribusi utama tegangan rendah) melalui $D P$ \{Distribution Panel atau panel distribusi) perlantai gedung, hingga menuju penyaluran beban ke setiap outlet ruangan dengan mengetahui elemen penting dari suatu sistem distribusi. Jenis pengaman yang dipakai dan sistem pendistribusian daya listrik serta karakteristik pembebanan.
Berdasarkan latar belakang dan permasalahan,Bagaimana hubunganantara pengaruh cadangan daya sistem terhadap tingkat gangguan selama sebulan di masingmasing lantai dalam kaitan tingkat keandalan pada Hotel Bisanta Bidakara, Surabaya.

\section{TINJAUAN PUSTAKA}

Menurut Sumarna (2011), Listrik cadangan daya sistem, Fasilitas ini harus telah membentuk cadangan sumber daya dan alternatif sumberdaya pengumpan dan sirkuit yang dibutuhkan di pusat data. Keamanan profesional harus memeriksa untuk mengontrol akses ke panel distribusi listrik dan pemutus sirkuit.

Menurut Rudyanto (2011), Definisi keandalan (Reliability) secara umum merupakan kemungkinan sistem akan mampu berfungsi dengan baik untuk jangka waktu tertentu. 
Menurut Joko (2011), Gangguan adalah kejadian yang menyebabkan pemutus tenaga trip tidak atas kehendak (tindakan) operator. Gangguan ada yang bersifat temporer dan ada yang bersifat permanen.

Menurut Djunaid (2012), Secara harfiah, kata hotel dulunya berasal dari kata HOSPITIUM (bahasa latin), artinya ruang tamu.

Menurut Septiawan (2012), Setiap gedung bertingkat memiliki konsep sistem distribusi kelistrikan yang berbeda-beda. Sistem tersebut di rancang dan dibangun untuk memasok daya listrik dimulai dari instalasi sumber sampai dengan instalasi beban.

\section{METODOLOGI PENELITIAN}

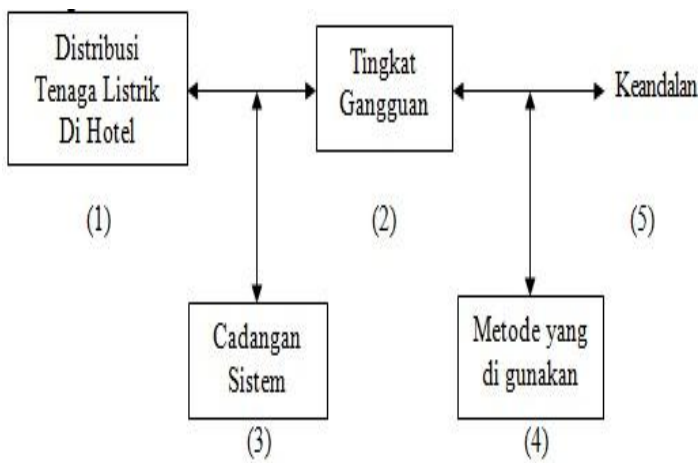

Gambar 1. Bagan alur penelitian

\section{Tahapan penelitian}

1. Pengamatan distribusi tenaga listrik di masing-masing lantai

2. Pengamatantingkat gangguan gangguan di line masing-masing lantai.

3. Pengamatan cadangan daya sistem di masing-masing lantai.

4. Pengamatan keandalan dalam distribusi tenaga listrik ke masing-masing lantai.

5. Pengamatan dan perhitungan Indeks Keandalan Dasar.

\section{HASIL DAN PEMBAHASAN}

Hasil pengamatan distribusi tenaga listrik di masing-masing lantai .

Tabel yang menyatakan hubungan antara lantai setiap tingkat dan pemakaian beban (dalam ampere).

\begin{tabular}{|c|c|c|c|c|}
\hline No. & PP Lantai & Standart & $\begin{array}{c}\text { Kapasitas di panel } \\
\text { (A) }\end{array}$ & $\begin{array}{c}\text { Pasokan beban } \\
\text { (A) }\end{array}$ \\
\hline 1 & Lantai 1 & 45,00 & 45 & 47,95 \\
\hline 2 & Lantai 2 & 32,00 & 32 & 47,95 \\
\hline 3 & Lantai 3 & 32,00 & 32 & 47,95 \\
\hline 4 & Lantai 4 & 45,00 & 45 & 47,95 \\
\hline 5 & Lantai 5 & 45,00 & 45 & 47,95 \\
\hline 6 & Lantai 6 & 50,00 & 50 & 47,95 \\
\hline 7 & Lantai 7 & 50,00 & 50 & 47,95 \\
\hline
\end{tabular}

Hasil pengamatan tingkat gangguangangguan di line masing-masing lantai.

Tabel yang menyatakan hubungan antara tanggal, waktu dan jenis gangguan.

\begin{tabular}{|c|c|c|c|c|}
\hline No. & Tanggal & Jam & Jenis gangguan & Lantai \\
\hline 1 & 2 & 3 & 4 & 5 \\
\hline 1 & $21-10-2013$ & 17.20 & 5top Kontak ngefong di kamar 625 & Lantai 6 \\
\hline 2 & $25-10-2013$ & 16.45 & Betukan stop kontak ngefong kamar & Lantai 5 \\
\hline 3 & $06-11-2013$ & 10.30 & MCB di floor teratai trip 3 buah & Lantai 3 \\
\hline 4 & $06-11-2013$ & 10.45 & MCB di floor melati trip & Lantai 2 \\
\hline 5 & $01-12-2013$ & 20.35 & Atasi MCB trip di kamar 303 & Lantai 3 \\
\hline 6 & $05-12-2013$ & 13.45 & Atagi konsleting di floor IV kamar 405 & Lantai 4 \\
\hline 7 & $07-12-2013$ & 15.10 & Betulkan MCB trip di floor melati & Lantai 2 \\
\hline 8 & $07-12-2013$ & 15.35 & Betukan MCB trip di kitchen & Lantai 1 \\
\hline 9 & $08-12-2013$ & 23.10 & Atasi MCB trip di kamar303 & Lantai 3 \\
\hline
\end{tabular}

Hasil pengamatan cadangan daya sistem di masing-masing lantai.

\begin{tabular}{|c|c|c|c|}
\hline No. & Lantai & Beban lantai (Watt) & Cadangan Daya (Watt) \\
\hline 1 & Lantai 1 & 10.550 & 3.300 \\
\hline 2 & Lantai 2 & 10.550 & 2.200 \\
\hline 3 & Lantai 3 & 10.550 & 2.200 \\
\hline 4 & Lantai 4 & 10.550 & 3.300 \\
\hline 5 & Lantai 5 & 10.550 & 3.300 \\
\hline 6 & Lantai 6 & 10.550 & 4.400 \\
\hline 7 & Lantai 7 & 10.550 & 4.400 \\
\hline
\end{tabular}

Hasil pengamatan keandalan dalam distribusi tenaga listrik ke masing-masing lantai .

Tabel yang menyatakan hubungan tanggal, jam gangguan, jam normal, jenis gangguan, masing - masing lantai dan keterangannya. 

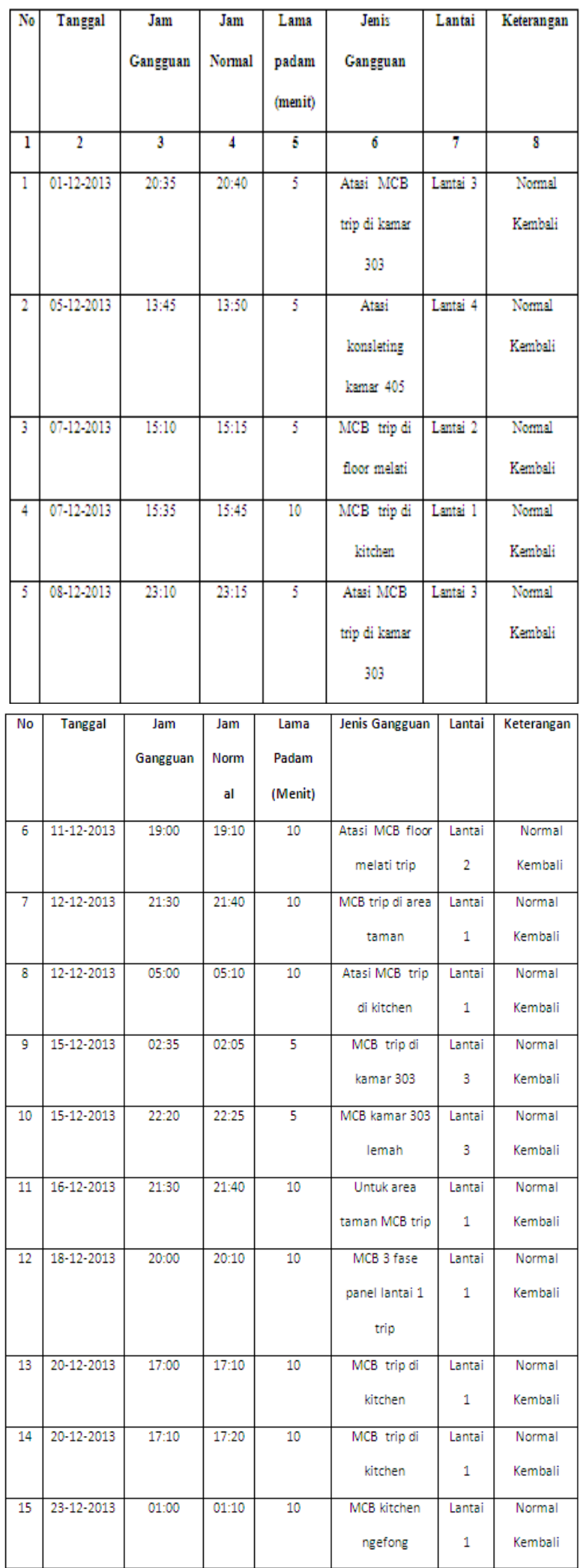

Hasil pengamatan dan perhitungan Indeks Keandalan Dasar.

\begin{tabular}{|c|c|c|c|c|c|c|}
\hline NO & $\begin{array}{c}\text { TANGGAL } \\
\text { PEMADAMAN }\end{array}$ & $\begin{array}{c}\text { PENYEBAB } \\
\text { PEMADAMAN }\end{array}$ & \begin{tabular}{|l} 
JUMLAH \\
PELANGGAN \\
PADAM
\end{tabular} & \begin{tabular}{|c|} 
MENIT X \\
JUMLAH \\
PELANGGAN
\end{tabular} & $\begin{array}{l}\text { LAMA MENIT } \\
\text { PADAM } \\
\text { RATA-RATA } \\
\text { (SAIDI) }\end{array}$ & $\begin{array}{l}\text { FREKUENSI } \\
\text { PADAM } \\
\text { RATA-RATA } \\
\text { (SAIFI) }\end{array}$ \\
\hline 1 & $01-12-2013$ & $\begin{array}{l}\text { Atasi MCB trip } \\
\text { di kamar } 303^{2}\end{array}$ & 1 & 5 & 0,71 & 0,14 \\
\hline 2 & $05-12-2013$ & $\begin{array}{c}\text { Atasi konsleting } \\
\text { kamar } 405\end{array}$ & 1 & 5 & 0,71 & 0,14 \\
\hline 3 & $07-12 \cdot 2013$ & $\begin{array}{l}\text { MCB trip di } \\
\text { floor melati }\end{array}$ & 1 & 5 & 0,71 & 0,14 \\
\hline 4 & $07-12 \cdot 2013$ & $\begin{array}{l}\text { MCB trip di } \\
\text { floor melati }\end{array}$ & 1 & 10 & 1,42 & 0,14 \\
\hline 5 & $08-12 \cdot 2013$ & $\begin{array}{c}\text { Atasi MCB trip } \\
\text { kamar } 303\end{array}$ & 1 & 5 & 0,71 & 0,14 \\
\hline 6 & $11-12-2013$ & $\begin{array}{l}\text { MCB trip di } \\
\text { floor melati }\end{array}$ & 1 & 10 & 1,42 & 0,14 \\
\hline 7 & $12 \cdot 12 \cdot 2013$ & $\begin{array}{l}\text { MCB trip di } \\
\text { area taman }\end{array}$ & 1 & 10 & 1,42 & 0,14 \\
\hline 8 & $12-12-2013$ & $\begin{array}{l}\text { MCB trip di } \\
\text { area taman }\end{array}$ & 1 & 10 & 1,42 & 0,14 \\
\hline 9 & $15-12 \cdot 2013$ & $\begin{array}{l}\text { MCB trip di } \\
\text { kamar } 303\end{array}$ & 1 & 5 & 0,71 & 0,14 \\
\hline 10 & $15-12-2013$ & $\begin{array}{l}\text { MCB trip di } \\
\text { kamar } 303\end{array}$ & 1 & 5 & 0,71 & 0,14 \\
\hline 11 & $16-12-2013$ & $\begin{array}{c}\text { Untuk area } \\
\operatorname{taman} \text { MCB trip }\end{array}$ & 1 & 10 & 1,42 & 0,14 \\
\hline 12 & $18-12-2013$ & $\begin{array}{l}\text { MCB } 3 \text { fase } \\
\text { panel lantai } 1 \\
\text { trip }\end{array}$ & 1 & 10 & 1,42 & 0,14 \\
\hline 13 & $20-12-2013$ & $\begin{array}{l}\text { MCB trip di } \\
\text { kitchen }\end{array}$ & 1 & 10 & 1,42 & 0,14 \\
\hline 14 & $20-12 \cdot 2013$ & $\begin{array}{l}\text { MCB trip di } \\
\text { kitchen }\end{array}$ & 1 & 10 & 1,42 & 0,14 \\
\hline 15 & $23 \cdot 12 \cdot 2013$ & $\begin{array}{l}\text { MCB kitchen } \\
\text { ngefong }\end{array}$ & 1 & 10 & 1,42 & 0,14 \\
\hline \multicolumn{3}{|c|}{ Jumlah } & 15 & 120 & 17,04 & 2,1 \\
\hline
\end{tabular}

\section{Pembahasan}

Dari Tabel distribusi tenaga listrik memiliki beban di masing - masing lantai dari lantai 1 sampai 7 , yang membutuhkan daya, antara lain :

- Lantai 1 Terdiri dari 10 kamar. Masingmasing kamar memiliki fasilitas :

1. Televisi CRT 32" dengan kebutuhan daya: 135 Watt

2. Kulkas mini merk Toshiba Glacio : 110 Watt

3. 6 buah lampu penerangan merk Philips: 30 Watt

4. AC 1PK merk Panasonic: 660 Watt

Kebutuhan daya listrik 1 kamar : 935 Watt

5. 1 lantai menggunakan 1 alat pemanas air merk Solahart dengan kapasitas 300 liter: 1200 Watt

Total Kebutuhan listrik lantai 1 per 10 kamar: 10550 Watt

Dari Tabeltingkat gangguan di line masingmasing lantai adalah : 
Tanggal 21 - Oktober - 2013 jam 17:20 terjadi gangguan stop kontak ngefong di kamar 625 di Lantai 6 dan telah di atasi sama teknisi, kondisi menjadi normal kembali.

Tanggal 25 - Oktober - 2013 jam 16:45 terjadi gangguan stop kontak ngefong di kamar 528 di Lantai 5 dan telah di atasi sama teknisi, kondisi menjadi normal kembali.

Dari Tabelcadangan daya sistem di masingmasing di masing - masing lantai yaitu :

Lantai 1 memiliki cadangan daya 3.300 watt di karenanakan sangat besar daya yang dipakai yaitu ada coffee shop, longe dan karaoke, room pendingin (Chiller), room reception, ruang lobby, room $\mathrm{HRD}$, room Manager ME (mechanical engineering), kitchen, musholah, room marketing, workshop khusus ME (mechanical engineering), ruang genset, pos security.

Dari tabel 4.4. terlihat bahwa Keandalan distribusi tenaga listrik ke masing-masing lantai, antara lain :

Tanggal 01 - Desember - 2013 , Terjadi gangguan MCB trip di kamar 303 terletak di lantai 3 jam 20:35, kemudian tim dari teknisi hotel bertindak membenahi gangguan tersebut hanya dengan waktu perbaikan 5 menit, kondisi gangguan tersebut telah menjadi Normal kembali jam 20:40.

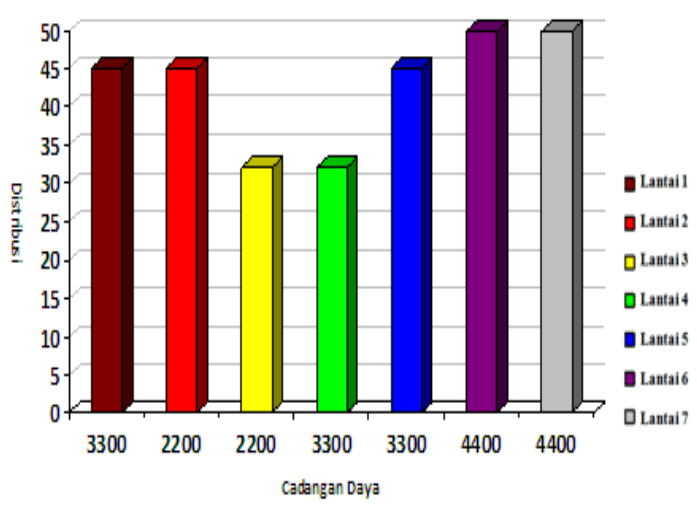

Grafik 4.1 hubungan antara distribusi, lantai dan cadangan daya.

Pada lantai 1, daya sebesar 3300 watt dan beban sebesar 45 ampere; Pada lantai 2, daya sebesar 2200 watt dan beban sebesar 32 ampere; Pada lantai 3, daya sebesar 2200 watt dan beban sebesar 32 ampere; Pada lantai 4, daya sebesar 3300 watt dan beban sebesar 45 ampere; Pada lantai 5, daya sebesar 3300 watt dan beban sebesar 45 ampere; Pada lantai 6, daya sebesar 4400 watt dan beban sebesar 50 ampere; Pada lantai 7, daya sebesar 4400 watt dan beban sebesar 50 ampere.

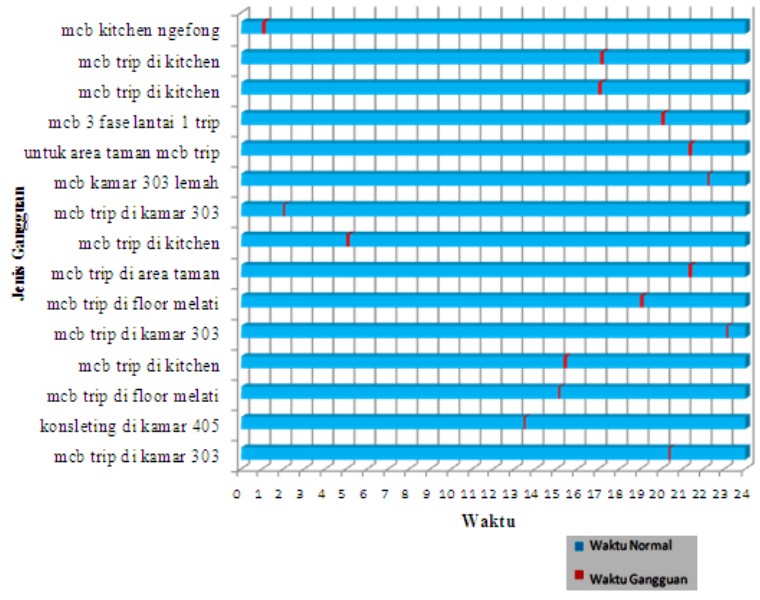

Tabel 4.4 hubungan antara jenis gangguan dan waktu.

Pada jam 20:35 terjadi gangguan di lantai 3 berupa mcb trip di room 303 dan maintenance di lakukan pada jam 20:35 sampai 20:40 dan gangguan kembali normal pada jam 20:40; Pada jam 13:45 terjadi gangguan di lantai 4 berupa atasi konsleting di room 405 dan maintenance di lakukan pada jam 13:45 sampai 13:50 dan gangguan kembali normal pada jam 13:50; Pada jam 15:10 terjadi gangguan di lantai 2 berupa MCB trip di floor melati dan maintenance di lakukan pada jam 15:10 sampai 15:15 dan gangguan kembali normal pada jam 15:15; Pada jam 15:35 terjadi gangguan di lantai 1 berupa MCB trip di kitchen dan maintenance di lakukan pada jam 15:35 sampai 15:45 dan gangguan kembali normal pada jam 15:45.

\section{KESIMPULAN}

Berdasarkan hasil dan pembahasan indeks keandalaan pada Hotel Bisanta Bidakara, Surabaya maka besarnya untuk SAIDI (harga rata-rata) adalah 17,04 gangguan per 
lantai dalam 1 bulan. Dengan mengacu pada PT. PLN (Persero) Distribusi Jawa Timur, Cabang SurabayaTahun 2014, Area Surabaya selatan yang menetapkan Realisasi SAIDI 16,72 menit per pelanggan, maka besarnya SAIDI di Hotel Bisanta Bidakara, Surabaya masih jauh dari harapan yang diinginkan. Untuk SAIFI besarannya 2,1 jam per lantai, dengan mengacu pada PT. PLN (Persero) Distribusi Jawa Timur, Cabang Surabaya Tahun 2014, Area Surabaya Selatan yang menetapkan lama gangguan Realisasi SAIFI 0,018 menit per pelanggan, maka besarnya SAIFI di Hotel Bisanta Bidakara, Surabaya masih jauh dari harapan yang diinginkan. Dengan memperhatikan kedua hasil perhitungan di atas, maka di kategorikan sistem keandalaan di Hotel Bisanta Bidakara, Surabaya perlu di rehabilitasi keandalannya.

\section{DAFTAR PUSTAKA}

1. Arief, Agung, " Analisa Keandalan Transformator Gardu Induk Wilayah Surabaya", JURNAL Vol 2 No.1. Jurusan Teknik Elektro ITS, Surabaya, 2011.

2. Firdaus, Muhammad. 2009. "Study Keandalan Sistem Jaringan Distribusi 20 KV"Teknik Elektro, JURNAL Sinergi, Vol.6 No.1 Mei 2009 ISSN 1436-2331.

3. Muslihin, Sugiyantoro Bambang, Harnoko, 2010, "Evaluasi Keandalan JTM $20 \mathrm{KV}$ Di Wilayah APJ Kudus" JURNAL PENELITIAN TEKNIK ELEKTRO Vol. 3 No.3, September, FT UGM.

4. Pulungan Ali basrah, Sukardi, Tambun Dahlan Prinando, 2012, “ Keandalan Jaringan Tegangan Menengah $20 \mathrm{KV} \mathrm{Di}$ Wilayah Area Pelayanan Jaringan (APJ) Padang PT. PLN (PERSERO) Cabang Padang" JURNAL NASIONAL TEKNIK ELEKTRO No.1 Vol: 1 September 2012, ISSN: 2302-, Teknik Elektro, Universitas Padang.

5. Sthenli Novian. 2010. " Analisa Kehandalan Sistem Kelistrikan ", Teknik Elektro, JURNAL Vol 10.
Sekolah Tinggi Nasional Yogyakarta. Yogyakarta.

6. Wicaksono Henki Projo, I.G.N. Hernanda Satriyadi 2012. "Analisis Keandalan Sistem Distribusi Menggunakan Program Analisis Kelistrikan Transien dan Metode Section Technique “ JURNAL TEKNIK ITS Vol. 1, No. 1 (Sept. 2012) ISSN: 23019271. Jurusan Teknik Elektro, Fakultas Teknologi Industri, Institut Teknologi Sepuluh Nopember (ITS).

7. Wins, Charles. 2009 "Pengaruh Kawat Terhadap Jaringan Distribusi $20 \mathrm{KV}$ dengan menggunakan ETAP ". Teknik Elektro. JURNAL vol. 10 NO.2

8. Wiwied Putra Perdana, 2009 " Evaluasi Keandalan sistem Tenaga Listrik pada Jaringan Distribusi" Jurnal EECCIS Vol. III, No. 1, Juni 2009.

9. Yanuar, Agung 2012. “ Studi Analisis Keandalan Sistem Distribusi Tenaga Listrik Surabaya" JURNAL TEKNIK POMITS Vol. 1 No.1, (2012) 1-5, Teknik Elektro, Fakultas Teknik Industri, ITS, Surabaya.

10. Badan Standarisasi Nasional " Persyaratan Umum Instalasi Listrik “, Yayasan PUIL, Jakarta, Tahun 2000. 